\title{
Exploiting Short Stories in the EFL Classroom
}

\author{
SELINA RAHMAN \\ SAYMA ARJU
}

\begin{abstract}
:
The purpose of this article is to focus on the effectiveness of using short stories in language instruction. Some instructors may think that teaching EFL is just to focus on linguistic benefits only and eventually their learners will communicate in the target language. On the other hand, instructors who have tried to accumulate literature in the curricula have observed that literary texts add a new dimension to the teaching of EFL. Short stories, for example, come to a great help for learners to learn the four skills-reading, writing, speaking and listening. In addition, with short stories, instructors can motivate learners to learn some literary aspects, cultural awareness and can make them think critically. However, before introducing the short stories instructors should realize the benefits of using this material and design their lessons that can meet the needs of their learners.
\end{abstract}

\section{Introduction}

The use of literature to teach foreign / second language has been given much emphasis to over one century. In our country in the yesteryears learners of second/foreign languages would translate literary texts to their native language to understand it and the instructors used to apply all traditional methods along with the grammar translation method to teach language. The other methods such as the direct method, the community language learning, the silent ways and the natural approach were rather less applied or not applied at all to teach literature as materials in second/foreign language. 
EFL instructors have been using literature in classrooms since 1980s. The aim of this article is to look at some of the issues and ways in which literature can be exploited in EFL classroom.

\section{Why is literature?}

First of all, we should consider the definition of literature where literature covers stories, poems and plays and especially those that have value of art and not just entertainment.

Many authors, critics and linguists have set their opinion on what literature is. One broader explanation of literature says that it is the reflection of different aspects of society as well as cultural documents to understand deeply of a country or countries.

\section{Why use literature?}

Critics and authors have defined the use of literary texts in many ways. Here are a few of them:

- Literature is authentic material

- Literature encourages interaction

- Literature expands language awareness

- Literature educates the whole person

- Literature is motivating

Myuskens suggested that instructors can use literary texts for language practice, reading comprehension and possible aesthetic appreciation. In addition to this he has also suggested that literary texts may be utilized for the development of knowledge of world literature, practice in reading and discussing creative work and the introduction of literary concepts, genres, and terminologies and other stylistic features (413). Moreover, literary texts are helpful and 
effective for learners to leading critical thinking by taking a trip from the text to their own minds.

Language class especially literature based often seems tiresome due to students non active participation. It happens that almost in every class there are some students who are really enthusiastic but there may be some other (may be they are very few in number) who lazily keep their books open in front of them and even don't feel to follow the text while one of their mates takes the labor of reading it aloud. This carefree attitude of the learners always haunts us with question like: what happens if some do and some don't? It is for sure that a lesson remains beyond success if a thing like this happens repeatedly and frequently. In order to get an active response from each and every participant of the class we have to focus on different task based activities suitable for EFL class. In designing these activities we must target to focus on and to explore the learners' descriptive, narrative, argumentative and analytical competence. Our main concern for this paper is to suggest some activities applicable in a practical classroom situation where a short story is the text.

\section{Reasons for using short stories}

Research shows many good reasons of using short stories. Amongst them here are a few:

- Motivating

- Teach culture

- Introduce literary concepts

- Teach critical thinking

Apart from all these benefits instructors should bear in mind the pris-tine benefit and that is reinforcement of skills. 


\section{Reinforcing the skills:}

According to Murdoch short stories can provide quality text content which will greatly enhance ELT courses for learners. He explained how instructors can design activities for writing acting out dialogues (9-17). Oster points out that literature helps learners to write more creatively (85). Instructors can plan a variety of writing activities to help learners to improve their writing skills. Activities such as, dialogue writing, summarizing, paraphrasing and many more can be added with these.

In addition, learners' vocabulary and reading can be improved by stories. Tasks designed on word form, antonyms/synonyms, meaning etc. may help learners to get most of the text. Learners also are profited from short stories for speaking skill. They may have opportunities to come up with their own ideas and views and speak up in front of the class which in one sense build their confidence as well as improve fluency what leads them to critical thinking. They become more creative and can speak confidently.

In order to improve the listening skill instructors can ask learners to read aloud. They can set some questions based on structure used in the text which learners will answer prior to their listening.

It is expected that each learner must show his emotional response towards a literary text. He must have the capacity to discover his emotional attachments as well as his intellectual explanation towards it. To reinforce this activity some language based task like comment on linguistic pattern, discourse pattern, use of words (formal/informal), and some literature based tasks like comment on the end or on title, content or theme (as for example: organization of the body of the story, comparing the very text with any other of 
the similar kind), character analysis by commenting on individual or comparing it with other and commenting on any especial incident may be offered and done in the class.

\section{Motivating learners:}

Elliot stated that literature motivates advanced students if they can genuinely engage with its thoughts and emotions and appreciate its aesthetic qualities (197). Vandrick listed one of the reasons for using literature is to explore their feelings through experiencing those of others (1). Literary texts are often more interesting than the texts found in course books. According to Clanfield "Literature is motivating------- literature holds high status in many cultures and countries. For this reason, students can feel a real sense of achievement at understanding a piece of highly respected literature. Also literature is often more interesting than those are found in the course book" (pars.9). As a result instructors should agree that short stories encourage students to feel a real sense of achievement and certainly the result is motivating.

For Schulz in selecting stories which are appropriate for learners' language level of proficiency, instructors avoid "Frustrational reading" (44). In order to choose stories learners' preferences should be considered and stories should have various themes. Akyel and Yalchin points out that variety of themes will offer different things to many individuals' interests and tastes (178).

\section{Teaching culture:}

Short stories can transmit culture of the people about whom the stories were written. By learning about the culture, learners get chance to know about the past, and present, and about peoples' customs and traditions. At this stage of teaching instructors must be 
aware of the culture of the people for whom the text was meant. Learners may have a tendency to compare and contrast their own culture to the other one. They should avoid misinterpretation of the target language and the culture.

\section{Teaching critical thinking:}

Of all the enjoyable reasons of using short stories, critical thinking is the most exciting one. Learners of advanced level can analyze what they have read; therefore they start thinking critically.

Howie agrees with the use of short stories to teach critical thinking. At this stage of teaching instructors may have the responsibility to help learners to develop the cognitive skills in them. By reading and writing, they develop their critical thinking skills (24).

\section{Maintaining momentum:}

For completion (thorough reading and analytical discussion) of any literary text it is very difficult to maintain momentum other than a complete lesson plan. In planning activities there must be rooms for home reading, taking feedback (connecting the present section with the previous one); presenting new section and practicing in class etc. In order to save time and to spend more time on discussion we largely have to depend on home reading. Besides some class discussion is directly happened immediately after the students' home reading. But home reading always needs to be monitored by some followed by works like answering some open-ended short questions, answering some quiz type of questions either in oral or in written form .In this stage the instructor must invite comments with arguments from the learners. Of course, this session will be followed by a correction session guided by the instructor. At the later part of open discussion students may be engaged in reading 
some criticisms on the text for preparing themselves for oral or written presentation.

Some instructors want that their students should read the text previously or at least be informed about the text before attending the class. For them class activities will be totally centered on discussion but we like to advance or proceed with text and discussion simultaneously. A sample lesson plan may be like the following:

\section{Lesson Plan}

Level: undergrad students

Topic: A short story (selected by the instructor. While selecting any text the instructor should make sure that the story contains enough sentences based on the same grammar pattern that $\mathrm{s} /$ he aims to teach in the class.)

Aim: Reading Skill: Understanding the fact/plot

Grammar Practice: Planned by the instructor

Listening Skill: Listen to the other learners

Writing Skill: answering questions (open ended and critical)

Speaking Skill: Taking part in the discussion

Total Class- Three; one hour and twenty minutes each. (The text should be divided into three parts depending on the theme or plot.)

\section{Lesson-1:}

- Pre-reading activities

- Reading first part

- Identifying difficult words and discuss literary items while reading 
- Pointing out summery key- arrange them in a flow chart following the gradual development of the plot.

- Invite students' argument

- Fix home reading

\section{Lesson-2:}

- Feed back on home reading-answering quiz type of questions

- Correction

- Commenting on particular character or incident that was identified in the previous lesson

- Pointing out the transitional devices that keep relation between the facts of the story.

- New lesson-reading and analysis: discourse and plot

- Answering anticipated questions-deserves personal opinion

- General discussion-on fact or character or behavior

- Fix home reading

\section{Lesson-3:}

- Feedback session (questions for forward thinkingguessing the next happenings)

- Tell back activities to bring the whole story to the class.

- Presenting new lesson

- Open discussion on some fix topics like-plot, character, social structure and social prejudice, view on particular idea, major characteristics of the piece etc.

- Writing activity

- Announcing project 


\section{Pre reading activities:}

In pre reading activity a short detail of cultural and social scenario in which context the story has been written is essential. A comparative study of it with the learners' own culture and values can provide a better effect. The instructors may take pause here as few learners always have either some opinions or some arguments to support their own believe ideals and values. Here if they get a room to express themselves, their opinion and views may often assist the class for their upcoming lesson.

For any literary text our first attraction goes to the author's biography. A short detail of the author's biography along with the social, political or personal influence and the context that directly inspire to write the particular piece helps the students to understand the authors' mood. Our next work is to highlight the characters. A brief analysis of each character may show both the internal and essential relationship among them. For getting a visual effect a flow chart showing tie among characters may help.

\section{Forward with activities:}

For reading short stories it is a privilege that it brings its readers to the end much sooner than any other types of prose text like novels or plays. Though the chief motivation for reading literature is getting pleasure, the lesson must be designed focusing on the learners' needs. Lesson of each session will start with a link with the previous activity. It either may be based on previous discussions that took place in the class or absolutely on home reading. The instructor must invite students' personal opinions, reactions or explanations towards the fact happened in the previous lesson. Arrival of any new character must be traced and noted. Next work 
might be a problem solving session based on previous lesson. Any kind of query is welcomed and appreciated here. Now if the learners do not have any question to ask, the instructor will take initiative to carry on the session for a while by throwing some predefined questions to the class. Unless getting satisfactory answers, hints for correct answers should be written on the board.

Generally we feel like to start a new lesson with reading. A student is allowed to read out the text to the whole class. Reading aloud leads to useful listening practice for foreign learners, as reading aloud at the same time engage us in both activities: reading and listening. Correction will take place repeatedly from the teachers' part including putting emphasis, expressing certain emotions to create suitable atmosphere which will inspire students to respond to the text and let them be involved in it. However, silent reading may be appropriate on certain occasions. The instructor must fix the part that $\mathrm{s} /$ he wants to read out in the class. It must be indicated in her/his lesson plan as well. It is obvious that the new lesson brings some new information for the class; the learners work is to relate them with their previous knowledge and to rearrange the fact every moment while it progresses (though a very few number of students have already read some parts of the text in advance to satisfy their personal interest). Works like noticing the details for identifying character development and plot development must be encouraged along with it. A piece of good description and narration must be marked. To ensure better understanding students are asked to paraphrase that particular part. At the starting this work may seem difficult to the students but once they get used to it, it will not be a hard job. Usually the student who goes on to paraphrase the last part is the most privileged one, since in the mean time the whole class became motivated to show their performance. Beside this 
activity some matters deserve peer attention and explanation, as any literary item occasionally contains moral lesson, philosophy, author's personal belief, any social prejudice that needs to be altered immediately etc. It is the instructor's duty to highlight these things and to explain those to the class with necessary supports and examples.

Next work for the class may be task based. Task like finding out double meaning of certain words; style of certain discourse including the punctuation marks; any adjective that applied for describing any character or any activity; any incident that deserves comment or may invite argument; any literary item used in that particular part and so on are appropriate for the stage. This step focuses on the identification of rhetorical aspects such as general pattern of text organization and macrostructure or scaffolding, as well as the use of the use of cohesive signals, different syntactic patterns, particular lexical items, and expressions that illustrate the language. Likewise the learners' attention should be drawn to the stylistic devices and the tone of the story. By guiding the learner to focus on these formal aspects of the language, we will be training his/her respective abilities and understanding of the indicators and additional meanings. It is not that in every session the class will practice all these activities, the instructor will select two or three items fit for each session. After every lesson (based on each new part of the text) the instructor will write the highlights or summary keys on the board. In doing so, students will supply the key ideas in order to assist the teacher. This discussion session may continue with some anticipated questions. Anticipated questions lead the learners to skim through the text, for they generally begin with whquestions. Answers of these sorts of questions should be very short in length though they will be persuasive enough to encourage the 
students to express their own opinion and expressions. These answers will help answering analytical questions which are aimed to answer at the next step. In order to encourage the learners to come up with their own opinion the instructor may pick out some interesting incidents for general discussion which will motivate the learners to react. The instructor will let them think what will happen if this incident occurs in their own lives or in their own country. Because of their excessive excitement, the language of the learners' response may be straight forward. Here the instructor will take labor to choose appropriate diction so that it will sound more gentle and appropriate.

\section{Writing Activity:}

Writing activities aim at writing comprehensive writing. It stimulates their thinking and they learn about literature by writing. Some question focusing on the text may offer for initial written task. Therefore, writing summaries, writing letter/e-mail showing personal feelings about the content and the writer's attitude and style are also appropriate for this part. Later on analysis on the general issues that make any particular character some way different or especial from other characters are also alright for the purpose of written activity.

\section{Project presentation:}

Producing project is an activity better done in group. Each group will be assigned with one specific aspect, of course based on the recently finished text. Learners may have the option choosing their own topic while the instructor will guide them to select a title. Topics like commenting on the plot development; commenting on the protagonist character, comparing the text with a similar one etc. 
may work here. For commenting on the plot students have to know the whole story with its diversions. A flow chart on events as they took place in the story may help a lot while impression that is created by the main character through activities, personal belief, his target and philosophy of life will help to comment on this very character. Similarities as well as dissimilarities among the protagonist character and other characters from the same story or from other stories written by the same author need to be discussed here. For doing any project work the learners will show the outlined plan of the whole project to the instructor. After getting the checked and corrected copy from the instructor they will proceed with their activities. The instructor will show them the way of using references, quotation, placing supporting materials like source card, note card, outline plan etc. Besides special projects should be fostered to enrich and expand the learner's command of the language and knowledge of specific topics. For planning and writing a project students require time; therefore, they should be asked to submit it at any time fixed by the instructor after the completion of the text.

\section{Conclusion:}

Since the aim of EFL teaching is to help learners to communicate fluently in the target language, instructors should focus not only on linguistic benefits but also on other issues. In addition to language learning instructors teach culture and make the learners creative thinkers. Finally, integrating short stories into the curriculum will help holistic development of EFL learners since these stories teach more than the skills which are necessary for survival in the target language. 


\section{Works Cited}

Akyel, A. and E. Yalcin. "Literature in the EFL class: A Study of Goal Achievement in Congruence." ELT Journal 44.3(1990): 174-180.

Elliot, R. "Encouraging reader-response to literature in ESL situations." ELT Journal 44.3 (1990): 191-198.

Crystal, Arbogast. "Hobnail." East of the Web Contributors. 20002-2003. 11 Nov. 2008

<http://www.eastoftheweb.com/short-stories/UBooks/ Hobn.shtmlm> .

Howie, S. H. "Critical Thinking: A critical skill for students." Reading TODAY 24 (1993): 24.

Lindsay, Clandfield. "Using literature in teaching English as a foreign /second language." The One Stop Magazine. 2006. 10 Mar. 2007 $<$ http://www. Onestopenglish.com/News/Magazine/Archive>.

Murdoch, G. "Exploiting well known short stories for language skills Development." IATEFL LCS SIG Newsletter 23(2002): 9-17.

Myuskens, J. A. “Teaching second-language literatures: Past, present and future." The Modern Language Journal 67(1983): 413-423.

O. Henry. "The Gift of the Magi." B \&L Associates. 1995-2007. Maine, USA. 11 Nov. 2008

<http://www. Classicshort.com/stories/magi.html Archive>.

Oster, J. "Seeing with different eyes: Another view of literature in the ESL class." TESOL Quarterly 23.1(1989): 85-103.

Schulz, R. A. "Literature and Readability: Bridging the Gap in Foreign Language Reading." The Modern Language Journal 65(1981): 43-53. 
Vandrick, S. "Reading and responding to novels in the university ESL

Classroom." The Journal of the Imagination in Language and

Teaching. 1997. 5 Mar. $2007<$ http://www.

Njcu.edu/CILL/vol4/vandrick.html >.

\section{$\underline{\text { Appendix }}$}

\section{Worksheets (for students)}

Topic: Short Story

Title: The Gift of the Magi by O. Henry (1862-1910)

Task-1: (Brain storming activity)

a. Analyze the key sentence: (guess the situation)

i. "One Dollar and Eighty Seven Cents. That was all." Related words:

- Hard ship

- Poverty

- Wish

- Sky high

- Fly in the sky

- Price hike

- Hard working

- Economy

- Economics etc.

ii. "Who give and receive gifts these two were wisest." Related Words:

- Occasion

- Magi

- Christmas

- Celebration

- Especial etc. 


\section{Task-2:}

Say whether the following sentences are true/false. If false write the right answers:

1. The rent of the house in which "Dillingham" couple lived was \$20/week.

2. When Jim returned home, he pressed the calling bell.

3. Della and Jim were the neighbors of King Solomon.

4. Jim used to wear a beautiful pair of gloves.

5. Della fried some chops as a part of their Christmas dinner.

\section{Task-3:}

Grammar focus (a) - Transitional words (a list of transitional words along with their functions will be provided to the class)

Read the following part of the story and underline the transitional words used in it:

"There was clearly nothing left to do but flop down on the shabby little couch and howl. So Della did it.Which instigates the moral reflection that life is made up of sobs, sniffles, and smiles, with sniffles predominating.

While the mistress of the home is gradually subsiding from the first stage to the second, take a look at the home."

\section{Task-4:}

Identify the function that the following words performed in the attached extract:

\begin{tabular}{|l|l|}
\hline \multicolumn{1}{|c|}{ Words } & \multicolumn{1}{c|}{ Functions } \\
\hline While & \\
\hline There was & \\
\hline
\end{tabular}




\begin{tabular}{|l|l|}
\hline But & \\
\hline So & \\
\hline And & \\
\hline That & \\
\hline
\end{tabular}

Task-5:

Use words from the box to complete the following sentences:

that, and , when, while, before , so , but

a. It's getting awfully late ------- it will be dark ------you make it home.

b. "Get your shawl Finnie. ---the sun goes down, it'll get chilly."

c. The only other comfort she had was the pretty rag doll ------ her mother had made for her.

d. Do not get down from a bus ------ it is in motion.

e. Rustling sounds from the brush caused Finnie to jump; ------ her mother's soothing voice calmed her fears.

f. -----, you are coming to join us at the party, right!

- Grammar focus (b) - Conditional sentence with if

e.g. "But if you'll unwrap that package you may see why you had me going a while at first."

- Grammar focus (c) - modal verb- be able to

e.g. "But she hugged them to her bosom, and at length she was able to look up with dim eyes and a smile and say: "My hair grows so fast Jim!"

\section{Task-6:}

Character analysis: Find suitable adjectives/expressions to describe Mrs. James Dillingham Young-

\begin{tabular}{|c|c|}
\hline $\begin{array}{l}{ }^{*} \text { Directly quoted from the } \\
\text { text }\end{array}$ & * Guess/use the shadow of the text \\
\hline $\begin{array}{ll}\text { 1. } & \text { Called as Della } \\
\text { 2. } & \text { pretty }\end{array}$ & $\begin{array}{ll}\text { 1. } & \text { miser } \\
\text { 2. } & \text { not educated enough }\end{array}$ \\
\hline
\end{tabular}




\begin{tabular}{|c|c|}
\hline $\begin{array}{l}\text { 3. has beautiful long hair } \\
\text { (like a golden cascade) }\end{array}$ & $\begin{array}{l}\text { 3. Let her be curved under the iron hand } \\
\text { of poverty. }\end{array}$ \\
\hline -------------- & ---- \\
\hline $\begin{array}{ll}5 . & - \\
6 & -\end{array}$ & $\begin{array}{ll}5 . & - \\
6 & -\end{array}$ \\
\hline
\end{tabular}

Task-7: (individual work)

Make a list of things/activities that you are planning to do to celebrate the upcoming Christmas day. Now write an e-mail to a friend informing him/her about your plan.

Task-8: (pair work)

Read the following extract-

"Pennies saved one and two at a time by bulldozing the grocer and the vegetable man and the butcher until one's cheeks burned with the silent imputation or parsimony that such close dealing implied."

Write an imaginary conversation between Della and a grocer/a vegetable man or a butcher (using present simple, present perfect, past simple, future with going to, conditional sentences-if). Word limit-110 